\title{
Punching shear design of RC flat slabs supported on wall corners
}

\section{Andri Setiawan | Robert L Vollum ${ }^{\circledR} \quad$ Lorenzo Macorini | Bassam A Izzuddin}

Department of Civil and Environmental Engineering, Imperial College London, London, UK

\section{Correspondence}

Robert L Vollum, Department of Civil and Environmental Engineering, Imperial College London, London SW7 2AZ, UK. Email: r.vollum@imperial.ac.uk

\begin{abstract}
Reinforced concrete buildings are typically braced with shear walls positioned around lift shafts and stairs. Vertical transfer of load from slab to walls leads to a concentration of shear stress in the slab at wall ends and corners, which needs to be considered in punching shear design. This issue is not addressed in EN 1992 (2004) and only partially addressed in fib Model Code 2010 leaving engineers to resort to their own judgment. Consequently, consideration of punching shear at wall corners can be overlooked entirely or not properly addressed through lack of knowledge. The paper addresses this issue by proposing a method for calculating the design shear stress at wall corners for use in conjunction with the Critical Shear Crack Theory. The method is initially validated against test results for slabs supported on elongated columns as well as numerical simulations. Subsequently, the method is extended to the punching design of a slab supported by a wall corner. The proposed analysis of the slab-wall corner junction is validated against the predictions of nonlinear finite element analysis (NLFEA) employing 3-D solid elements as well as the joint-shell punching model (JSPM) previously developed by the authors.

\section{K E Y W O R D S}

design procedure, finite element methods, punching
\end{abstract}

\section{1 | INTRODUCTION}

Design methods for punching shear typically compare the nominal shear stress calculated on a specified control perimeter with the design shear resistance. In general, the shear stress around the control perimeter is nonuniform even under concentric loading, as illustrated in Figure 1a for a wall end and in Figure $1 \mathrm{~b}$ for a wall corner. This nonuniformity of shear stress needs to be accounted for in

Discussion on this paper must be submitted within two months of the print publication. The discussion will then be published in print, along with the authors' closure, if any, approximately nine months after the print publication. design to achieve safe results. Most of the pertinent experimental campaigns in the literature examine the influence of large or elongated columns ${ }^{[1-5]}$ with almost no consideration of wall supports. Available studies show that the punching capacity of slabs supported on elongated columns is less than comparable slabs supported on columns having the same perimeter length but square or circular shape. This arises because the shear stress around the control perimeter becomes nonuniform ${ }^{[3]}$ as the support cross section (maximum dimension $c_{\max }$ ) becomes large relative to the slab effective depth $(d)$.

Under concentric loading, the need to account for nonuniform shear stress around supports depends on the proximity of the adopted control perimeter to the

This is an open access article under the terms of the Creative Commons Attribution License, which permits use, distribution and reproduction in any medium, provided 

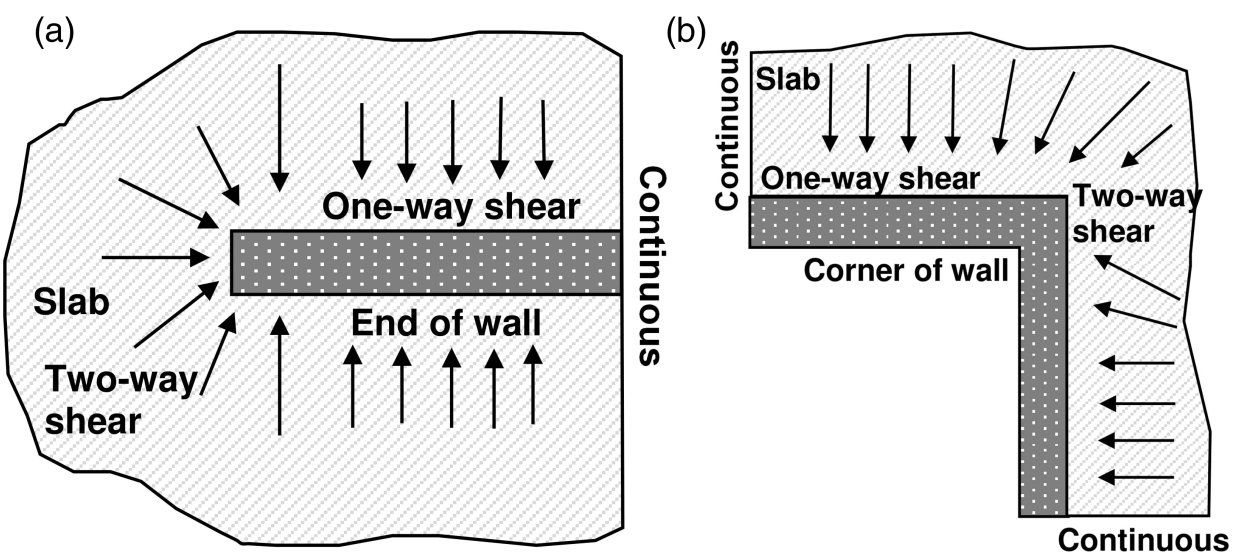

(a)
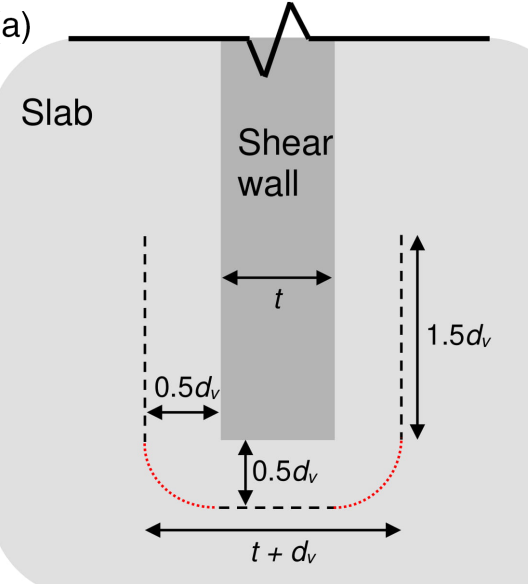

(b)

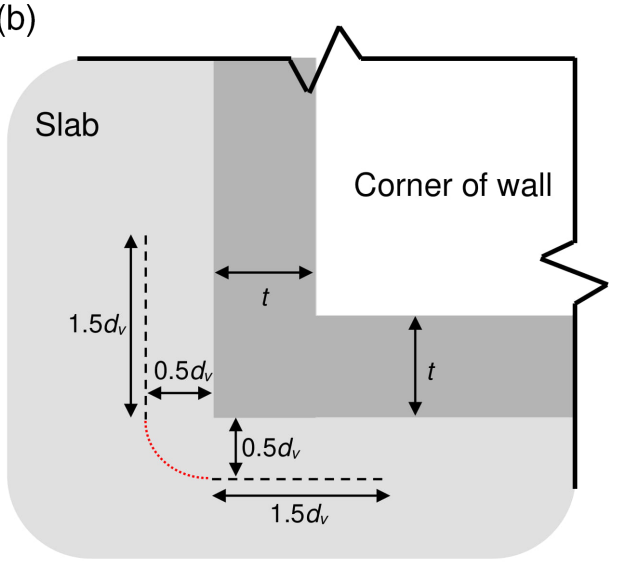

FIG U RE 1 One- and two-way shear forces transferred from the slab to the support at: (a) end of wall; (b) corner of wall
FIG URE 2 Control perimeter for checking local punching of slabs supported on: (a) wall end; (b) wall corner according to MC2010. Notes: $d_{v}$ is the effective slab depth for punching shear column. For example, EN $1992(2004)^{[6]}$ positions the control perimeter at $2 d$ from the column face where the shear force distribution under concentric loading is relatively uniform regardless of the support shape or size ${ }^{[1]}$. Consequently, EN 1992 (2004) includes no special provisions for large supports. On the other hand, when the control perimeter is positioned at $0.5 d$ from the column face,,$^{[7,8]}$ an explicit reduction factor is required to account for stress concentrations at support corners. For example, $\mathrm{MC} 2010^{[8]}$ limits the length of the straight segments along each edge of the full control perimeter $\left(b_{0}\right)$ to $3 d$ as shown in Figure 2 for various scenarios. The reduced control perimeter is depicted $b_{0,3 d}$ in MC2010 and throughout this paper. In the case of large columns, MC2010 assumes that the full design shear force is resisted by the reduced perimeter $b_{0,3 d}$ with no contribution from linear shear along the neglected straight lengths of the perimeter. As shown by Sagaseta et al., ${ }^{[3]}$ this approach works well for $\frac{c_{\max }}{d} \leq 6$ but becomes increasingly conservative for longer supports ${ }^{[9]}$. This paper proposes a procedure, based on shear field analysis, ${ }^{[10]}$ for estimating the design shear stress at the corners and ends of walls. The method is validated using available experimental data from punching tests on slabs with elongated supports as well as nonlinear finite element analysis. Subsequently, the method is used to examine punching failure at wall corners.

\section{SHEAR FIELD ANALYSIS OF SLABS SUPPORTED ON ELONGATED COLUMN}

\section{1 | Background}

Vaz Rodrigues et al. ${ }^{[10]}$ used shear field analysis to evaluate punching shear failure in bridge deck slabs. In this approach the design shear stress is obtained using linear elastic finite element analysis (LFEA) with shell elements. The shear field is a vector field representing the direction and magnitude of the principal shear force per unit length in $a \operatorname{slab}^{[10]}$. Vaz Rodrigues et al. defined the effective control perimeter length as:

$$
b_{0, e l a s t}=\frac{V}{v_{e l, m a x}}
$$

where $V$ is the total applied load and $v_{e l, \text { max }}$ is the maximum shear force per unit length acting perpendicular to 
the control perimeter. Equation 1 is conservative since it implies failure occurs when the peak elastic shear stress reaches the shear resistance whereas, in reality, some shear redistribution ${ }^{[3,9]}$ occurs around the control perimeter.

\section{2 | Refined shear field analysis}

This study refines the design procedure of Vaz Rodrigues et al. ${ }^{[10]}$ by accounting for the beneficial effect of shear redistribution. The refined method is intended for punching shear design at large columns as well as wall ends and corners. The key difference with the method of Vaz Rodrigues et $\mathrm{al}^{\left[{ }^{[10]}\right.}$ is that the design shear stress is taken as the average stress around the critically loaded quadrant of the effective control perimeter $b_{0,3 d}$ (for wall corners, see Figure $2 \mathrm{~b}$ ) rather than the peak stress. Studies by Setiawan ${ }^{[11]}$ show that the design shear stress calculated with LFEA depends significantly on the choice of element out-of-plane shear stiffness. To illustrate this, results are presented in Figure 3 for slab OC15 of Teng et al. ${ }^{[2]}$ which was analyzed using LFEA with ETABS $^{[12]}$. Slab OC15 measured $2,800 \mathrm{~mm} \times 2,200 \mathrm{~mm}$ $\times 150 \mathrm{~mm}$ with an effective depth of $114 \mathrm{~mm}$ and $c_{\text {max }} / d$ of 8.77. The slab was loaded with eight equal point loads evenly positioned around its perimeter. One quarter of the specimen was modeled using a uniform square mesh of $15 \mathrm{~mm}$. Seven shear stiffness multipliers were considered: 1.0 (unreduced); $0.8 ; 0.6 ; 0.4 ; 0.2 ; 0.15$, and 0.1 .

Figure 3 shows the resulting contours of shear force/ length $\left(v_{x z}\right)$ along the longer side of $1 / 4$ of a control perimeter located at $0.5 d$ from the column face. The broken-black line in Figure 3 indicates the parts of the control perimeter omitted by MC2010 (outside $b_{0,3 d}$ ) while the red line indicates the border between downward (yellow) and upward shear forces (green). Figure 3 shows that as the shear stiffness is reduced the border between downward and upward shear force shifts towards the slab centreline resulting in a more uniform shear force distribution. Through comparison with the results of NLFEA with solid elements using ATENA ${ }^{[13]}$, Setiawan ${ }^{[11]}$ found that using an out-of-plane shear stiffness modifier of between 0.2-.4 in LFEA provides estimates that are in better agreement with distribution of shear stress at failure from the nonlinear analyses. However, further study is required to justify the generality of this proposal.

\section{3 | Validation of the proposed method for long supports $\left(\frac{c_{\max }}{d}>6\right)$}

The proposed shear field method was used in conjunction with the Critical Shear Crack Theory (CSCT $)^{[14]}$ to predict the punching resistance of two-way loaded slabs with

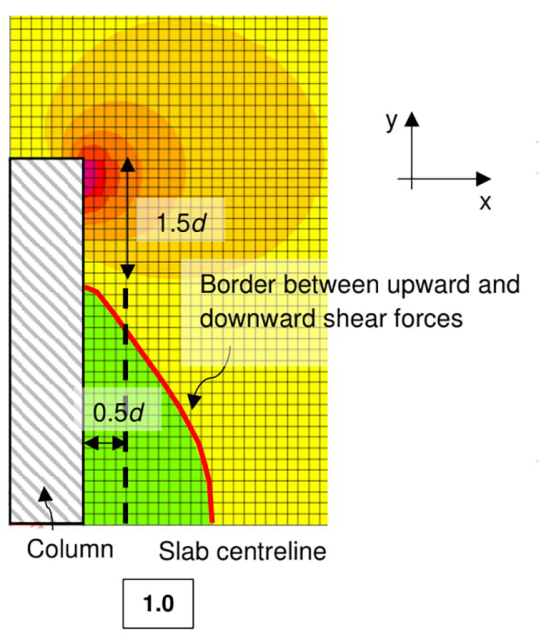

Shear forces/length in $10^{3} \mathrm{kN} / \mathrm{m}$
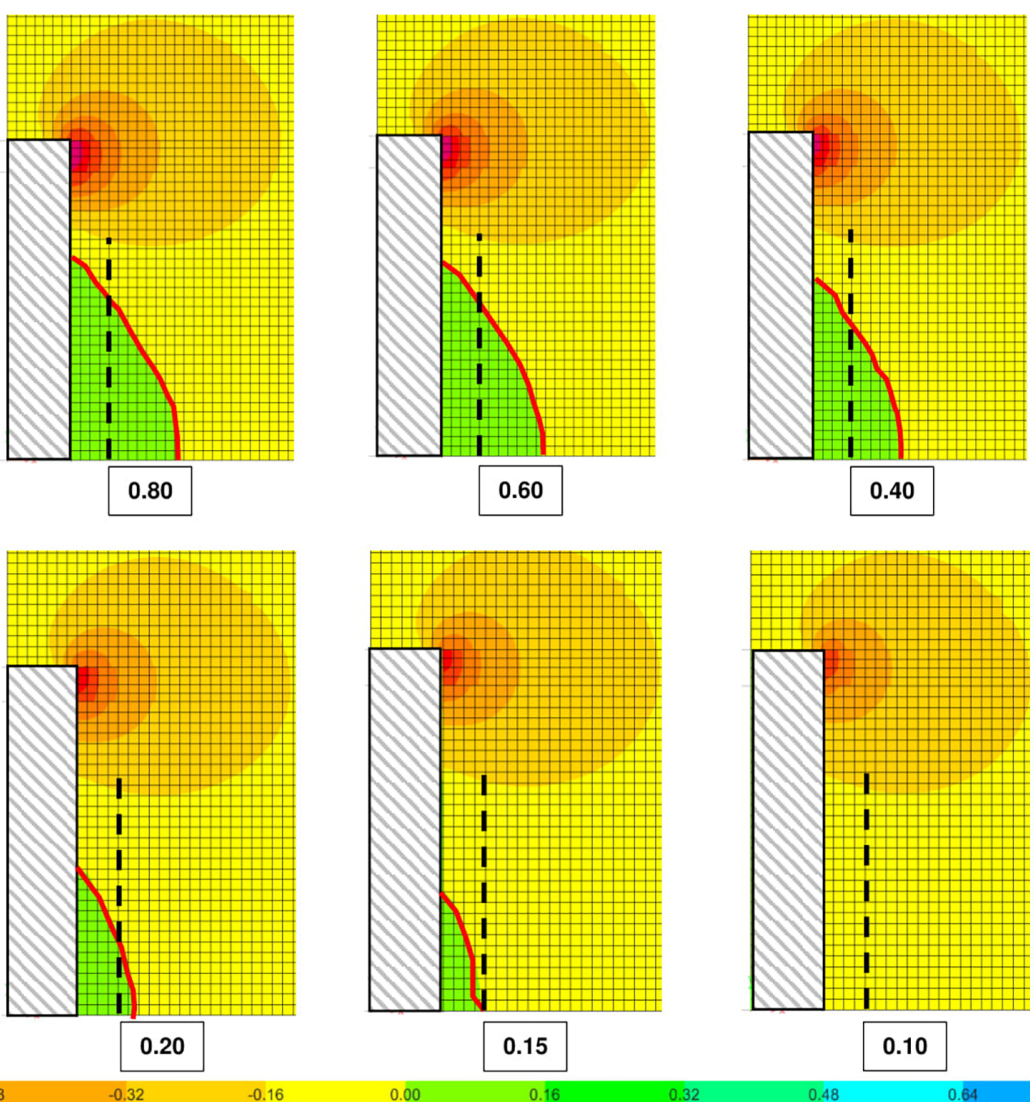

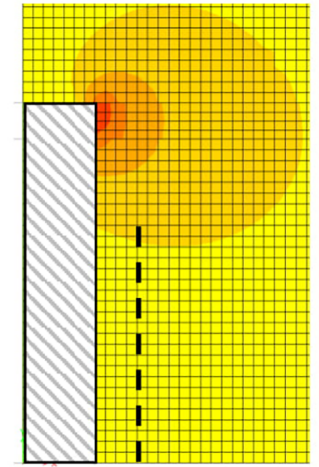

0.10

F I G U RE 3 Contours of shear forces/unit length $v_{x z}$ along the longer side of the control perimeter of OC15 for various stiffness modifiers (LFEA) 
$6.5 \leq \frac{c_{\max }}{d} \leq 10$ for which very few experimental data are available ${ }^{[9,11]}$. The analyzed slabs comprise: a) three previously tested slabs and $b$ ) four virtual slabs from the parametric study of Setiawan ${ }^{[11]}$. Shear force demand was taken as the average shear stress around $b_{0,3 d}$. This shear stress was calculated as $\frac{\left(V-V_{\text {staight }}\right)}{b_{0,3 d . d}}$ in which $V$ is the total column reaction and $V_{\text {straight }}$ is the shear force resisted by the straight lengths of the full control perimeter $b_{1}$ neglected in $b_{0,3 d}$. The force $V_{\text {straight }}$ was determined with LFEA. Based on comparisons with NLFEA solid element modeling, the out-of-plane shear stiffness modifier used in the LFEA was taken as 0.2 . The CSCT punching resistance was calculated in terms of the maximum slab rotation which was determined using MC2010 Level of Approximation (LoA) III and NLFEA (MC2010 LoA IV). The results of analyses using the proposed method (depicted "s.field") are shown in Figure 4a,b for the tested and virtual slabs respectively. Also shown are MC2010 predictions for which the demand shear force was calculated as $\frac{V}{b_{0.3 d}}$ (depicted "no one-way"). Additionally, Figure 4a shows the failure load of slab OC15 determined by Setiawan ${ }^{[11]}$ with 3 -D solid element modeling using ATENA. For slabs of Series b) in Figure $4 b$, the ATENA predictions of Setiawan ${ }^{[11]}$ are used as the strength reference. Figure 4 shows that the proposed method (depicted "s.field") gives reasonable yet conservative strength predictions. The increased strength given by the proposed method (2-10\%) compared with MC2010 ("no-one-way") is due to one-way shear becoming progressively more significant as the support length increases ${ }^{[9,11]}$. All the CSCT methods in Figure 4 include a degree of shear redistribution $^{[15]}$ unlike that of Vaz Rodrigues et al. ${ }^{[10]}$ in which the peak shear stress is assumed critical. Strength predictions obtained with rotations calculated using MC2010 LoA III and NLFEA are similar, which is convenient since LoA III only requires LFEA which is commonly used in design. The next section considers punching at a wall corner.

\section{3 | EXTENSION OF THE PROPOSED METHOD TO DESIGN SLABS SUPPORTED ON WALL CORNER}

\section{1 | Description of building geometry used to study wall-slab behavior}

This example considers a flat slab measuring $24.5 \mathrm{~m}$ square in plan supported on a central core and perimeter columns. As shown in Figure 5a, the perimeter columns are $500 \mathrm{~mm}$ square and evenly distributed around the building perimeter (a)

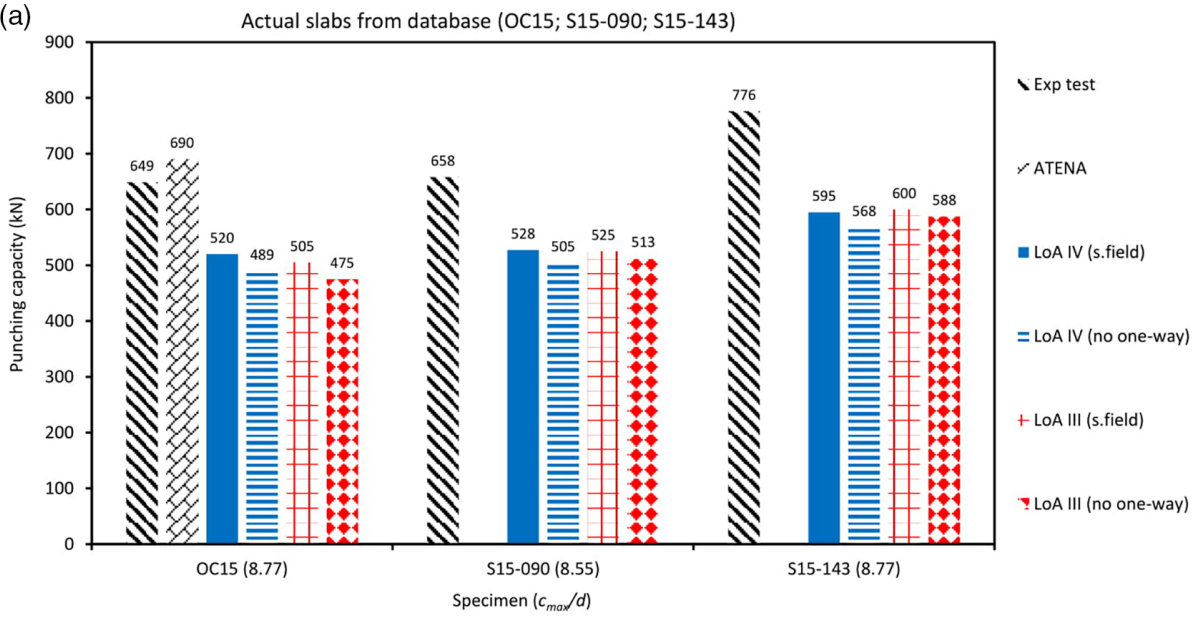

(b)

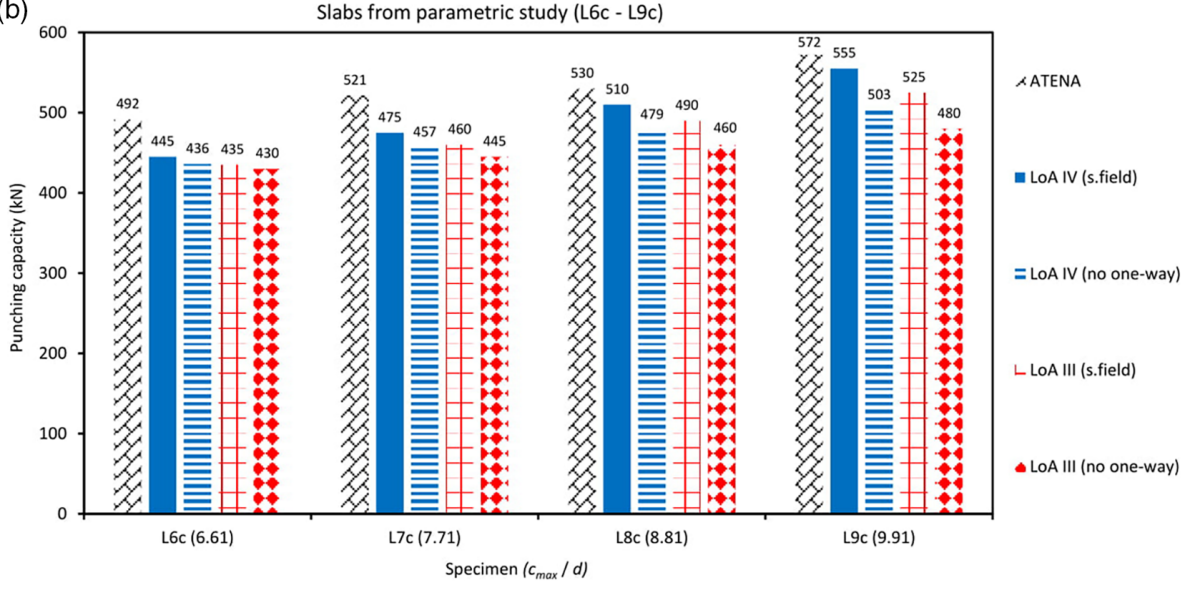

F I G URE 4 Comparison of classic (no one-way) vs. refined approach (shear field) of slabs with $\frac{c_{\max }}{d}>6.0$ from: (a) actual slab database; (b) parametric study 
(a)

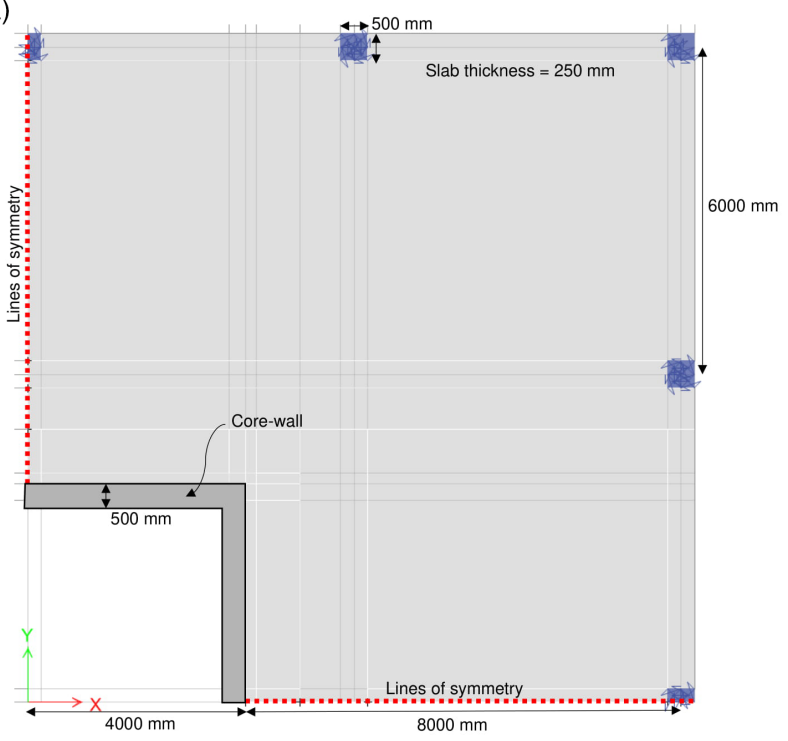

(b)

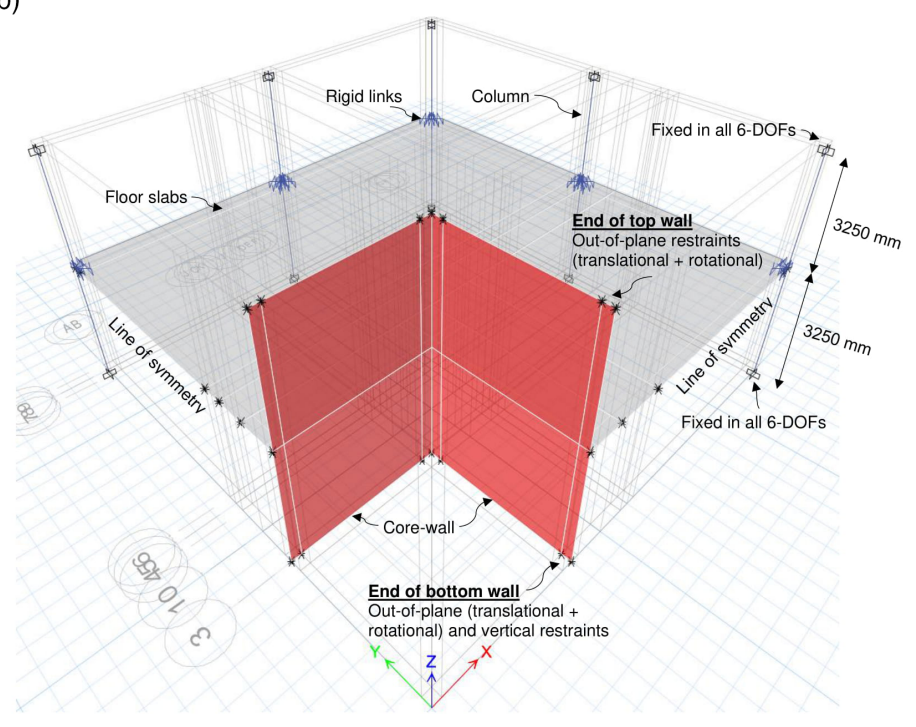

F I G U R E 5 Structural arrangement used to study wall-slab behaviour modeled in ETABS (a) Plan view; (b) 3-D view

F I G U RE 6 Illustration of typical extraction regions of shear force/length along the MC2010 effective control perimeter at wall corner

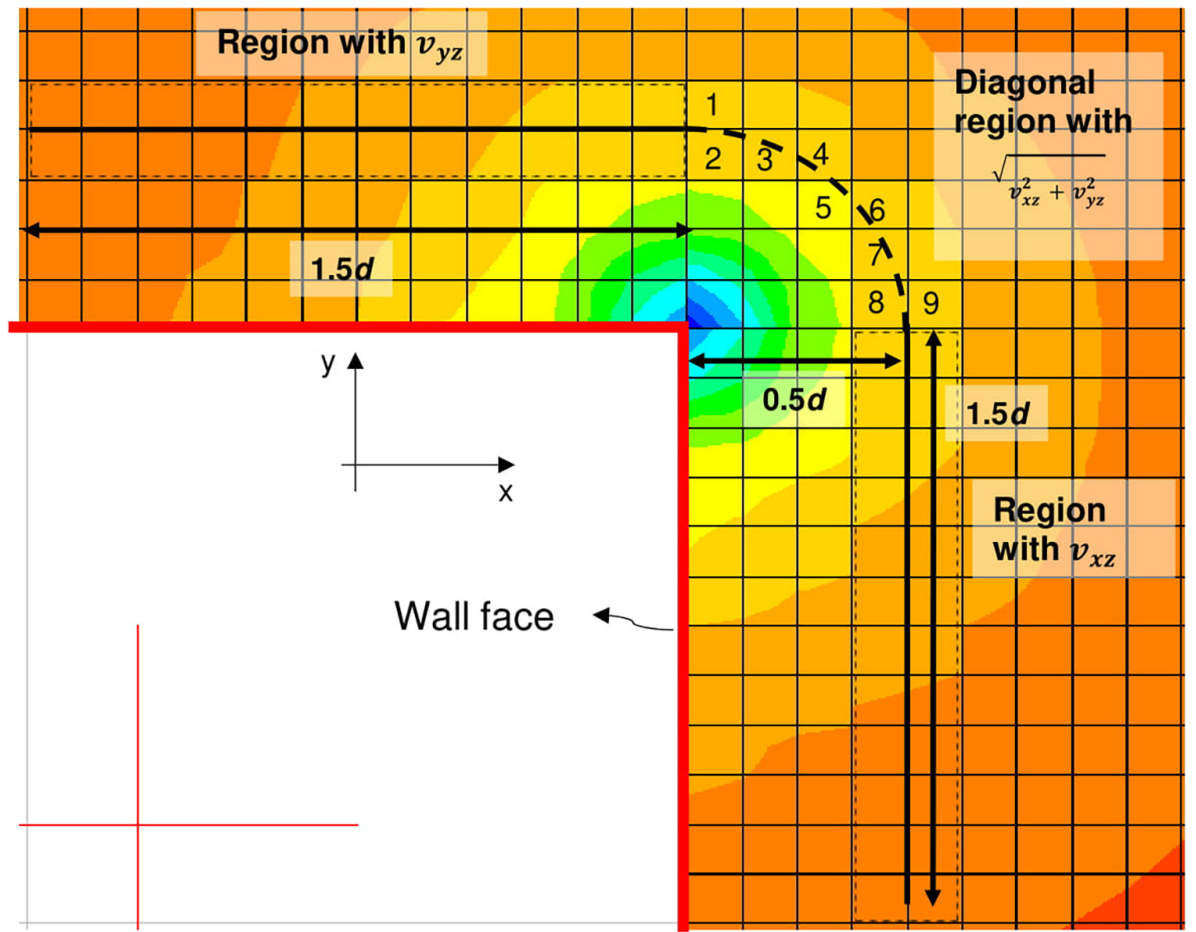

with floor-to-floor height of $3.25 \mathrm{~m}$ (see Figure 5b). The central core wall is idealized as a $500 \mathrm{~mm}$ thick square tube with outside dimensions of $8 \mathrm{~m}$. The slab, which is $250 \mathrm{~mm}$ thick with an average effective depth of $200 \mathrm{~mm}$, spans $8 \mathrm{~m}$ between the outside face of the wall and the centroid of the perimeter columns (see Figure 5a). The concrete class ${ }^{[6]}$ is C50/60 for wall and columns and C30/37 for the slab. The superimposed dead load (SIDL) and imposed load (LL) are $1.5 \mathrm{kN} / \mathrm{m}^{2}$ and $3 \mathrm{kN} / \mathrm{m}^{2}$ respectively while the external cladding load is $1 \mathrm{kN} / \mathrm{m}^{2}$. Concrete self-weight was calculated using a specific weight of $25 \mathrm{kN} / \mathrm{m}^{3}$. The design ultimate load was calculated as 1.35(SW + SIDL) + 1.5 LL where SW is the slab self-weight.

One quarter of the floor plate and supporting vertical structures were modeled in ETABS. Columns were modeled as line elements with their central nodes connected to the nodes of surrounding slab elements through rigid links extending to the column perimeter. The core wall and slab were modeled with shell-thick element type which considers out-of-plane transverse deformation according to Reissner-Mindlin plate theory. For ease of modeling, the shell elements 
(a)

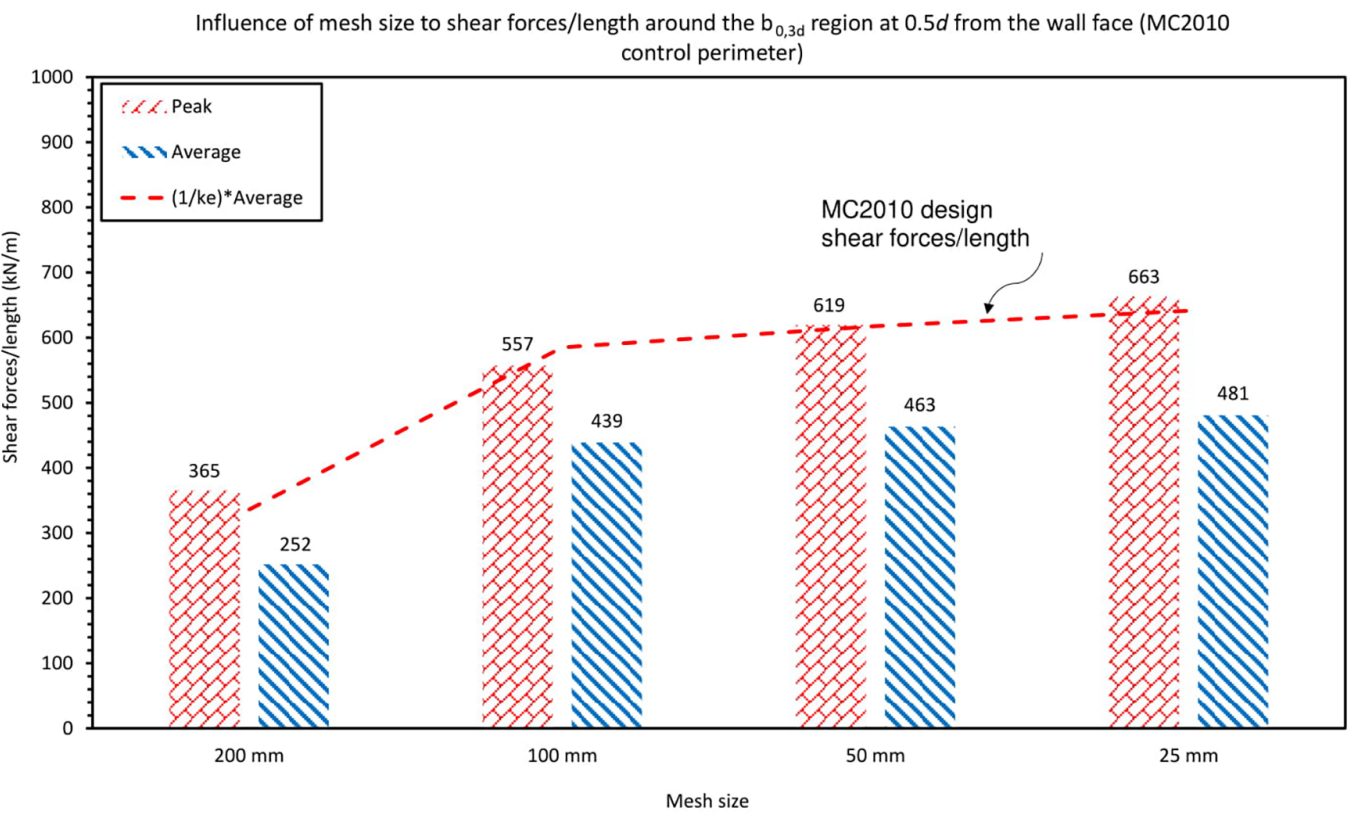

(b)

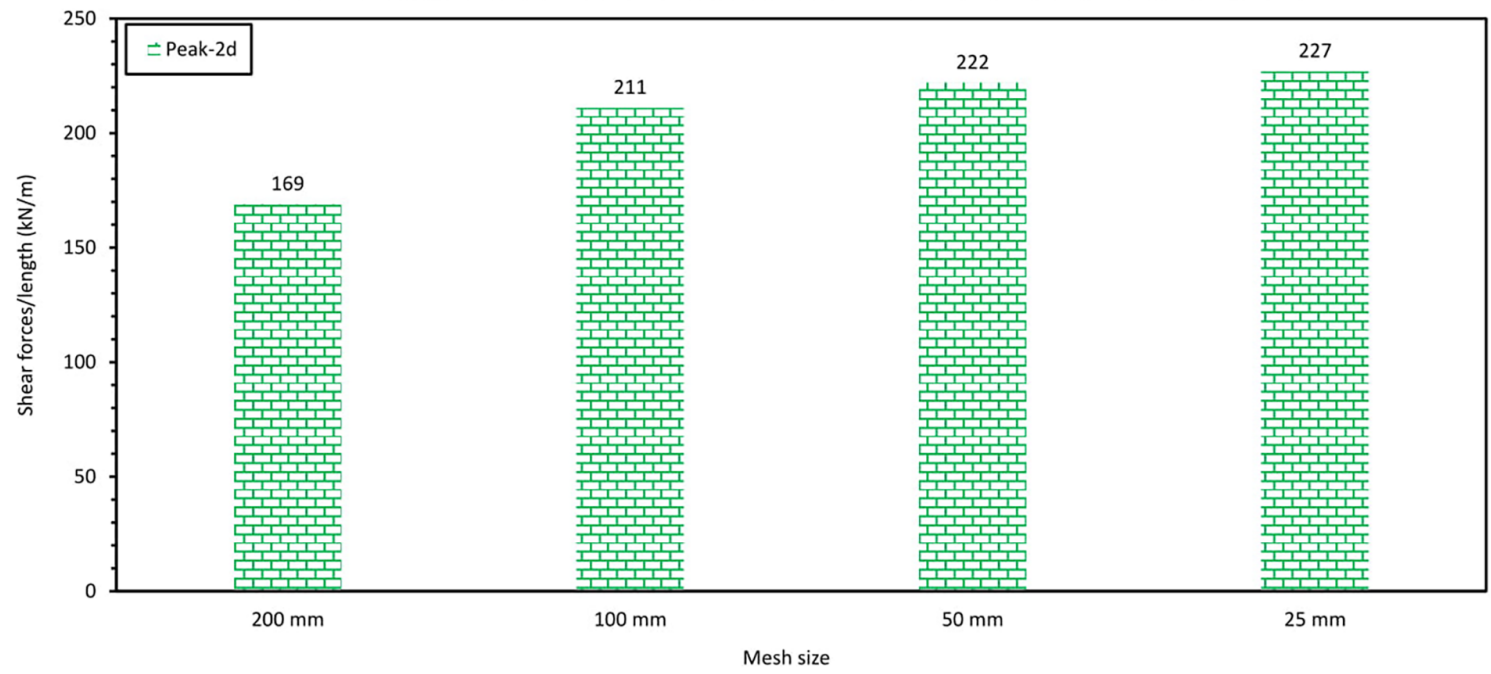

F I G U R E 7 Influence of mesh size on shear force per unit length at: (a) $0.5 d$ (MC2010 control perimeter); (b) $2 d$ (EN1992 control perimeter) from the wall face

representing the wall were positioned at the face of the wall. This simplified the modeling since it avoided the need to connect the shell elements to the slab edge using rigid links of length equal to half the wall thickness. Both top- and bottom-ends of the wall were restrained in the out-of-plane direction (translation and rotation) but only the bottom-end was vertically restrained. Top and bottom columns were rigidly restrained in all 6 degrees of freedom (see Figure 5b).

\subsection{Sensitivity study}

A sensitivity study was carried out to investigate the influence on shear stress of: 1) slab mesh size; 2) out-of- plane moment restraint of the wall and 3) slab stiffness modifiers. Each of these parameters was varied individually. Shear forces were extracted around control perimeters located at $0.5 d$ and $2 d$ from the wall face. The required shear force is that perpendicular to the control perimeter which equals $\sqrt{v_{x z}^{2}+v_{y z}^{2}}$ for rounded segments ${ }^{[10]}$ in which $v_{x z}$ and $v_{y z}$ are forces per unit length. Apart from concentric loading, each quadrant of $b_{0}, 3 d$ (see Figure 2) needs to be considered individually. The average shear force per unit length around the quadrant of $b_{0,3 d}$ under consideration is depicted $v_{\text {wall-ave }}$ while the corresponding average force around the curved segment of the quadrant (see Figure 6) is depicted $v_{\text {wall - peak }}$. Shear redistribution was not considered when assessing punching using EN 1992 for which the peak shear force 


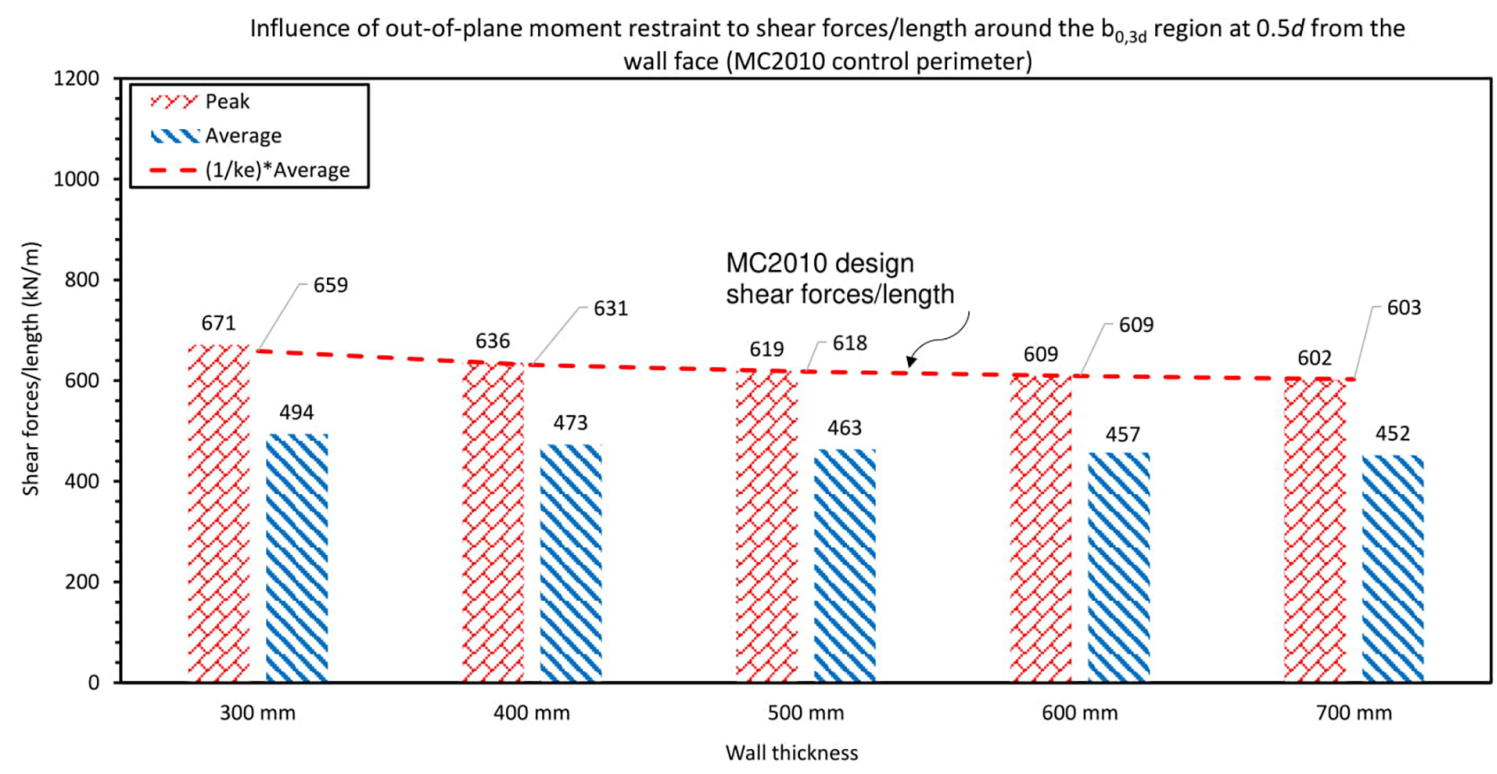

F I G U R E 8 Influence of out-of-plane moment restraint on shear force per unit length at MC2010 control perimeter

per unit length along a control perimeter at $2 d$ from the wall face (depicted $v_{\text {wall }- \text { peak-2d }}$ ) is consequently critical.

\subsection{1 | Sensitivity to mesh size}

Four meshes with uniform element sizes of 25, 50, 100 , and $200 \mathrm{~mm}$ were investigated. Shear forces per unit length were extracted along control perimeters positioned at $0.5 d$ ( $v_{\text {wall - ave }}$ and $\left.v_{\text {wall-peak }}\right)$ and $2 d$ $\left(v_{\text {wall }- \text { peak }-2 d}\right)$ from the wall face. Figure 7 a shows the resulting values of $v_{\text {wall - ave }}$ and $v_{\text {wall - peak }}$ for a control perimeter at $0.5 d$ from the wall face. The shear force $v_{\text {wall }- \text { peak }}$ is seen to be well estimated by $\frac{v_{\text {wall }} \text {-ave }}{k_{e}}$ where $k_{e}=0.75$ as suggested in MC2010 for corners of walls. The peak shear force per unit length at $2 d$ is shown in Figure $7 \mathrm{~b}$. Significantly for practice, the influence of mesh refinement is seen to be significantly more pronounced for the MC2010 control perimeter at $0.5 d$ than that of EN 1992 at $2 d$. In all subsequent LFEA analyses, a mesh size of $50 \mathrm{~mm}$ was adopted.

\subsection{2 | Sensitivity to out-of-plane moment restraint}

Out-of-plane support moment restraint to the slab depends on the wall out-of-plane bending stiffness. This was investigated for the MC2010 control perimeter by varying the wall thickness from its reference value of $500 \mathrm{~mm}$ to $300,400,600$, and $700 \mathrm{~mm}$. Figure 8 shows that the effect of this on the shear force per unit length at $0.5 d$ from the support face stress is relatively minor.

\subsection{3 | Sensitivity to slab stiffness modifiers}

Previous studies ${ }^{[3,10,15]}$ suggest that the slab torsional stiffness should be reduced by a multiple of 0.125 in LFEA to account for stiffness reduction due to cracking. The effect of this was investigated in ETABS by adopting stiffness reduction factors of 0.125 , both individually and simultaneously, for plate twisting $\left(m_{x y}\right)$ and in-plane shear $\left(f_{x y}\right)$. Figure 9a shows the influence of the adopted stiffness reduction factors on both the peak and average shear forces per unit length around the effective control perimeter. Reducing the $f_{x y}$ stiffness had no effect while reducing the $m_{x y}$ stiffness increased average and peak shear forces by an insignificant $2 \%$ and $4 \%$, respectively. In order to evaluate the influence of modifying the out-of-plane plate shear stiffness, which is shown to be significant in Section 2.2, four out-of-plane stiffness modifiers were evaluated: $0.8,0.6,0.4$, and 0.2. The results are presented in Figure 9b, which shows that both $v_{\text {wall - ave }}$ and $v_{\text {wall - peak }}$ decrease with decreasing slab outof-plane shear stiffness as found for elongated columns in Section 2.2. Comparison with NLFEA in Section 4 suggests that a reduction factor of 0.4 is justifiable. However, for practical design, it is suggested that the beneficial effect of reducing the out-of-plane shear stiffness is neglected. Figure 9a,b also show that $\frac{v_{\text {wall-ave }}}{0.75}$ reasonably approximates the peak shear force $\left(v_{\text {wall-peak }}\right)$ as found for elongated columns. 

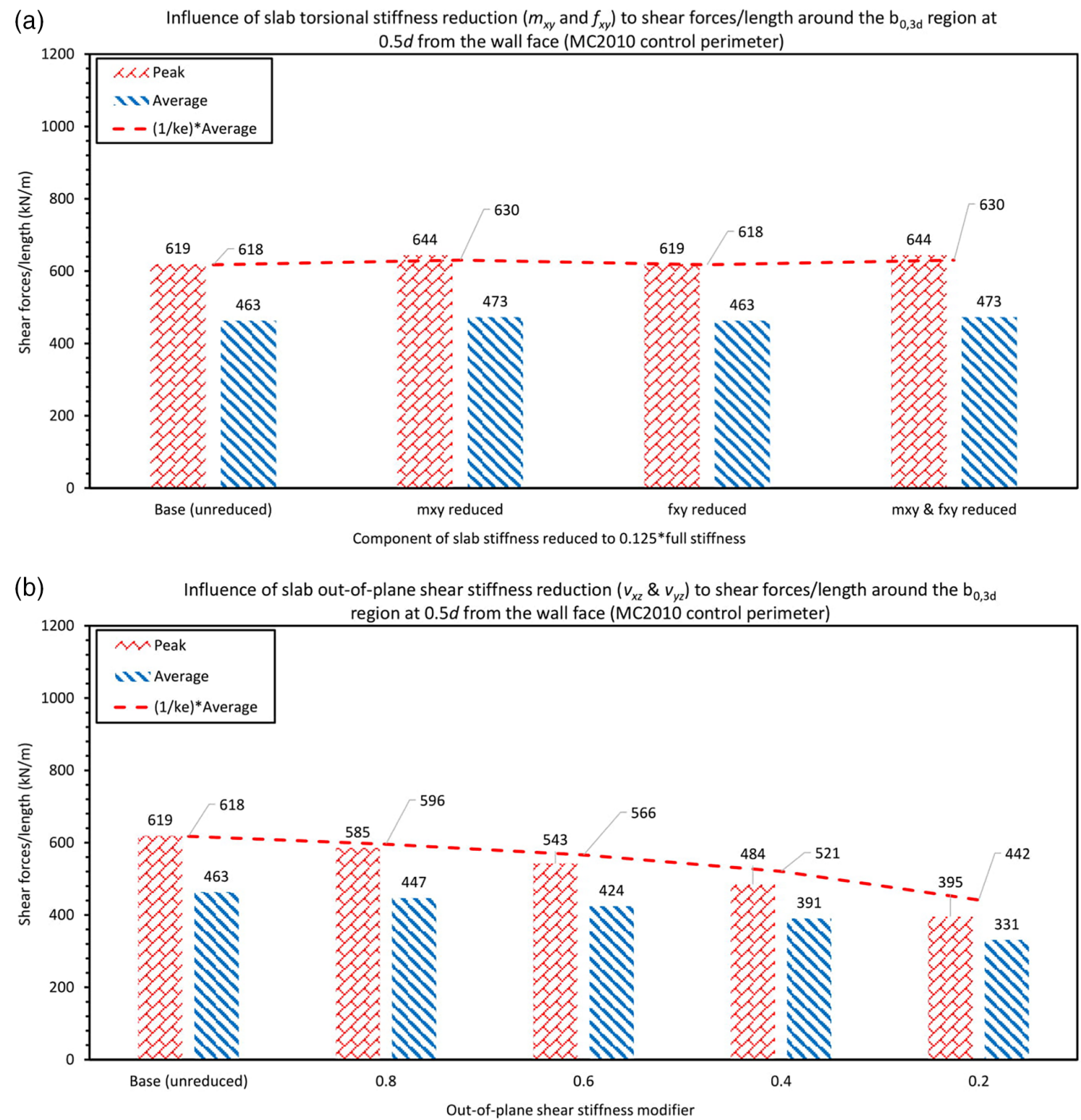

F I G U RE 9 Influence of slab (a) torsional and (b) out-of-plane stiffness modifiers on shear force/length at MC2010 control perimeter

\section{3 | Designing the required shear reinforcement around the wall corner}

Once the design shear force per length $v_{E d}$ is known, the need for shear reinforcement can be determined. This requires the shear resistance provided by concrete alone $v_{R d, c}$ to be determined.

For the CSCT, this is done using: (a) MC2010 LoA I, (b) MC2010 LoA III and the closed-form CSCT expression of Muttoni et al. ${ }^{[16]}$ with (c) standard and (d) refined input parameters. EN 1992 is also considered. Calculation of punching resistance using each of these approaches is described in Appendix S1. The shear resistance provided by the concrete depends on the flexural reinforcement ratio which was determined from bending moments calculated in the LFEA. Reinforcement areas were calculated within the support strip width $b_{s}$ (A.10) as required by $\mathrm{MC} 2010$. The resulting flexural reinforcement ratios were $0.89 \%$ at the support and $0.35 \%$ in the span. To validate the proposed procedure, comparative NLFEA was carried out using 3D solid elements with ATENA as well as the extended joint-shell punching model (JSPM) of the authors ${ }^{[9,17]}$.

\section{4 | NONLINEAR FINITE ELEMENT ANALYSIS (NLFEA) OF THE WALL- SLAB SPECIMEN}

For comparison with failure loads obtained with shear field analysis, the wall-slab specimen was analyzed with NLFEA using ATENA with 3-D solid elements as well as 
F I G URE 10 Mesh and boundary conditions of wall-slab model in ATENA (3-D solid)

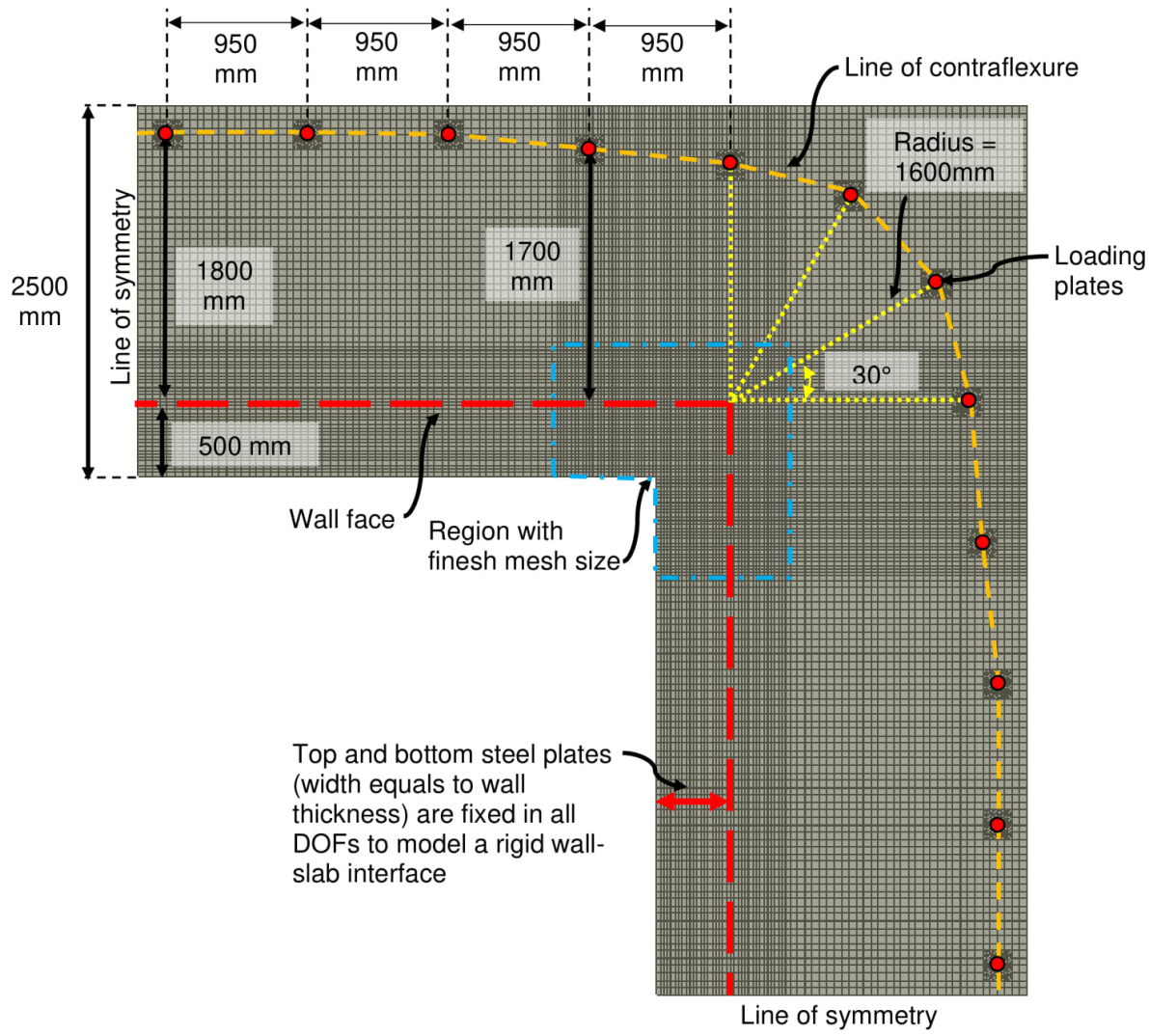

the joint-shell punching model (JSPM) of Setiawan et al. ${ }^{[9,17]}$. In each case, the slab was unreinforced in shear.

\section{1 | 3-D solid analysis performed in ATENA}

\subsection{1 | Numerical methodology and chosen boundary conditions of the 3-D solid model}

The NLFEA with ATENA ${ }^{[14]}$ was carried out following the procedure described previously by Setiawan et al. ${ }^{[17,18]}$, which was used in Reference 17 to analyze seventeen slabs without shear reinforcement having either square supports (14) or elongated supports (3). All the slabs failed in punching. The resulting mean value of $\mathrm{P}_{\text {test }} / \mathrm{P}_{\text {predicted }}$ was 0.953 with a coefficient of variation of $7.4 \%$. To reduce model size, the slab in Figure 5 was only modeled to just beyond the line of elastic contraflexure around which load was evenly applied through plates (see Figure 10). The wall support was modeled by clamping the top and bottom surface of the slab with vertically restrained steel plates having the same width as the wall. Based on previous studies, ${ }^{[9,17,18]}$ the slab was meshed with 10 linear brick elements (8-noded) through its thickness. A fine mesh with uniform size of $25 \times 25 \times 25 \mathrm{~mm}^{3}$ was used adjacent to the wall corner (see Figure 10). Loading and support plates were modeled using linear tetrahedral (4-noded) elements with elastic steel properties. Flexural reinforcement was modeled with embedded 1-D 2-noded linear truss elements assuming perfect bond. In ATENA, a fully rotating smeared crack approach was used in conjunction with concrete material model CC3DNonLinCementitious2, which combines constitutive models for tensile (fracture) and compressive (plastic) behavior. The Rankine tensile failure criterion was used with exponential softening. The input parameters used in the ATENA analysis are presented in Table 1. Vertical loads were applied uniformly to all loading plates in load-control using the Arc-Length method. The number of iterations was limited to 100 for each load step. The convergence tolerance was set at $1 \%$ for displacement, residual, and absolute residual error and $0.01 \%$ energy error as defined in Cervenka et al. ${ }^{14}$

\subsection{2 | Results of the 3-D solid analysis}

Localized punching shear failure is difficult to detect from the load-rotation response at wall ends and corners since no clear softening branch develops ${ }^{[9,19]}$. Consequently, the 
T A B L E 1 Summary of material parameters and numerical input for NLFEA in ATENA

\begin{tabular}{|c|c|c|}
\hline \multirow[t]{2}{*}{ No. } & Parameter & Value/reference \\
\hline & Concrete constitutive model & \\
\hline A1 & Concrete elastic modulus & Model Code $2010^{[8]}$ \\
\hline A3 & Concrete tensile strength & Model Code $2010^{[8]}$ \\
\hline A4 & Smeared crack model & Fully-rotating crack \\
\hline A6 & $\begin{array}{l}\text { Limit of compressive strength reduction due to } \\
\text { cracking }\end{array}$ & $0.8 f_{c}^{\prime}$ \\
\hline A7 & $\begin{array}{l}\text { Eccentricity (defining the shape of the failure } \\
\text { surface) }\end{array}$ & 0.52 \\
\hline \multirow[t]{2}{*}{ B2 } & Bond-slip model & Perfect bond \\
\hline & Loading procedure and convergence criteria & \\
\hline $\mathrm{C} 1$ & Loading procedure & Static (force-controlled) \\
\hline $\mathrm{C} 2$ & Iteration method & Arc-length method \\
\hline $\mathrm{C} 3$ & $\begin{array}{l}\text { Convergence criteria for displacement, residual, and } \\
\text { absolute residual error }\end{array}$ & $1 \%$ \\
\hline \multirow[t]{2}{*}{$\mathrm{C} 4$} & Convergence criteria for energy error & $0.01 \%$ \\
\hline & Mesh properties & \\
\hline D1 & Mesh size (finest) & $\begin{array}{l}25 \times 25 \times 25 \mathrm{~mm}(10 \text { elements along } \\
\text { height }) \text { at critical punching region }\end{array}$ \\
\hline
\end{tabular}

failure load was determined using the strain-based failure criterion of Setiawan $^{[9,11]}$ in which failure is assumed to occur when the radial strain in the slab soffit at $0.5 d$ from the wall face first drops to zero. This criterion is based on experimental observations ${ }^{[20-22]}$ that show that near failure the radial compressive strain in the slab soffit near the column face drops to zero or even goes into tension. The total wall reaction at failure was predicted to be 785.3 $\mathrm{kN}$. According to previous LFEA of the full floor model, the total wall reaction for the considered ULS load combination $(1.35(\mathrm{SW}+\mathrm{SIDL})+1.5 \mathrm{LL})$ is $746.6 \mathrm{kN}$. Thus, the ratio of concrete capacity (mean) to the force demand, $\lambda_{V}=\frac{785.3}{746.6}=1.05$. Figure 11a,b show the crack patterns (crack width $>0.1 \mathrm{~mm}$ ) and principal tensile strain respectively at the predicted failure load. At failure, tensile strain is seen to develop locally in the slab soffit near the corner of the wall as observed experimentally ${ }^{[20-22]}$ and in the authors ${ }^{[9,11]}$ analyses of elongated columns with ATENA.

\section{2 | Extended joint-shell punching model (JSPM) for long or large support scenario}

\subsection{1 | Brief background}

The JSPM of the authors ${ }^{[9,17]}$ simulates punching failure by combining 2-D nonlinear layered-shell elements with nonlinear joint elements located around a rectangular control perimeter positioned at $0.5 d$ from the column face. The joint shear resistance is calculated using the CSCT in terms of the slab rotation which is monitored throughout the analysis allowing the joint shear resistance to be updated at each load step. Individual joints fail once the joint shear force reaches the joint shear strength. Subsequently, the joint shear resistance softens in accordance with the CSCT. Shear redistribution and post-punching resistance are realistically simulated using this modeling strategy ${ }^{[17]}$. At large supports with $c_{\max } / d$ 
between 3 and 6 , dummy joints with minimal resistance are provided along the straight segments of perimeter discarded by MC2010 in $b_{0,3 d}$ (see Figure 2). Calibration studies $^{[9,11]}$ show this approach to work well. However, for $c_{\max } / d>6$ the contribution of linear shear becomes significant along the discarded straight lengths of the reduced perimeter $b_{0,3 d}$. In this case, one-way joints are inserted along the discarded straight lengths of the control perimeter that are further than $1.5 d$ from the support corners (see Figure 12a). The one-way joint shear resistance is conservatively taken as that given by the model of Cavagnis et al. ${ }^{[24]}$ at first yield of flexural reinforcement. The accuracy of the JSPM has been established ${ }^{[9,11,18]}$ by modeling the punching failure of 61 slabs from the literature of which 24 had $c_{\max } / d>3$ including six with $6<c_{\max } / d<9$. In order to extend the database, Setiawan ${ }^{[11]}$ simulated a further four virtual slabs with $6 \leq c_{\max } / d \leq 10$ with ATENA. The mean failure criterion of Muttoni ${ }^{[14]}$ was used to calculate the twoway joint shear resistance in all these analyses. The resulting mean value of $\mathrm{P}_{\text {test }} / \mathrm{P}_{\text {predicted }}$ for slabs with $c_{\max } / d<3$ is 1.01 with a coefficient of variation of $10.3 \%$. For slabs with elongated supports having $3 \leq c_{\max } / d \leq 10$, the mean and covariance of $P_{\text {test }} / P_{\text {predicted }}$ are 0.99 and $11 \%$. For $c_{\text {max }} / d<6$, the JSPM gives similar strength predictions to MC2010 Level of Approximation IV provided the same CSCT resistance function is used. For longer supports MC2010 becomes progressively more conservative, due to the neglect of one-way shear, unless shear field analysis is used as described in the next section for a slab supported on a wall corner. In this paper, the joint shear resistance is determined using mean material parameters and partial material factors of 1.0. The JSPM is implemented ${ }^{[9,17]}$ in the nonlinear structural analysis program ADAPTIC ${ }^{[23]}$.

\subsection{2 | Analysis of floor plate using the JSPM}

A quarter of the floor plate was modeled with nonlinear shell elements ${ }^{[25-26]}$ in ADAPTIC ${ }^{[23]}$ following the procedure described by Setiawan et al. ${ }^{[17]}$. The slab was modeled from the wall face up to mid-span where the slab was rotationally restrained. A uniform mesh of $100 \mathrm{~mm}$ was used as shown in Figure 12b. The wall was modeled using spring elements which for consistency with the LFEA were positioned along the slab edge at the junction with the wall face. The spring stiffness was calculated in terms of the uncracked wall stiffness neglecting reinforcement. For consistency with the LFEA, stiffnesses were calculated assuming that the wall was fully restrained at each floor level as shown in Figure 5b.
The axial component of the spring stiffness (per unit length of wall) was calculated as:

$$
K_{\text {axial }}=\frac{E t}{h}
$$

where $\mathrm{E}$ is the Young's modulus of concrete, $\mathrm{h}$ is the floor-floor wall height and $t$ is the wall thickness.

The out-of-plane rotational stiffness (per unit length of wall) was calculated as:

$$
K_{\text {rotational }}=2 \cdot \frac{4 E I}{h}=\frac{2}{3} \cdot \frac{E t^{3}}{h}
$$

The out-of-plane translational stiffness (per unit length of wall) was calculated as:

$$
K_{\text {translational }}=2 \cdot \frac{6 E I}{h^{2}}=\frac{E t^{3}}{h^{2}}
$$

The constitutive models and material properties adopted in ADAPTIC for concrete, reinforcement bars and joints were as used previously ${ }^{[9,17]}$. Two- and one-way joints were positioned around a control perimeter located at $0.5 d$ from the wall face as shown in Figure 12a. As previously described, the $1.5 d$ gap between the one- and two-way joints in Figure 12a is necessary to avoid overestimate of shear resistance due to excessive shear redistribution ${ }^{[9,11]}$. The slab was uniformly loaded and punching failure was assumed to occur when the last two-way joint failed within the $b_{0,3 d}$ region (see Figure 12a). Failure occurred at a load factor $\lambda_{V}$ of 0.94 . Figure 13a-c show the variation of shear force/ length, perpendicular to the control perimeter, along the $b_{0}$, ${ }_{3 d}$ (see Figure 12a) region predicted by ATENA and the JSPM at $0.20,0.90$, and $1.0 P_{u}$ where $P_{u}$ is the total predicted wall reaction at failure from ATENA. Also shown is the shear force/length acquired using LFEA with out-of-plane shear stiffness modifiers of 1.0 and 0.4 (depicted "LFEANOMOD" and "LFEA-0.4MOD," respectively). At $0.20 P_{u}$ the slab behaves elastically so the ATENA prediction agrees well with LFEA-NOMOD (see Figure 13a). However, with approaching failure $\left(0.90-1.0 P_{u}\right)$, the JSPM and LFEA0.4MOD shear forces compare favorably with ATENA (see Figure 13b,c). Comparison of the LFEA results in Figure 13, without and with stiffness modifier, shows that reducing shear stiffness has the effect of reducing the peak shear force and redistributing shear force away from the wall corner. This redistribution of shear force with increasing load is also evident in the ATENA results shown in Figure 13. In ATENA, the shear stiffness is dictated by the level of damage within the concrete which increases with load. Conversely, the shear stiffness is independent of load in the 
(a)

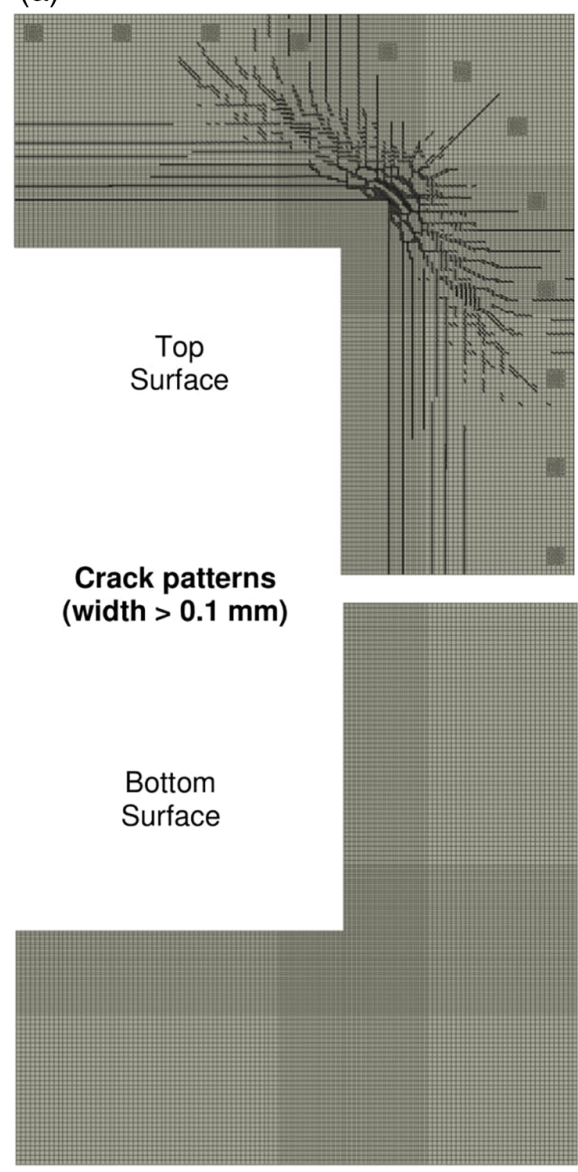

(b)

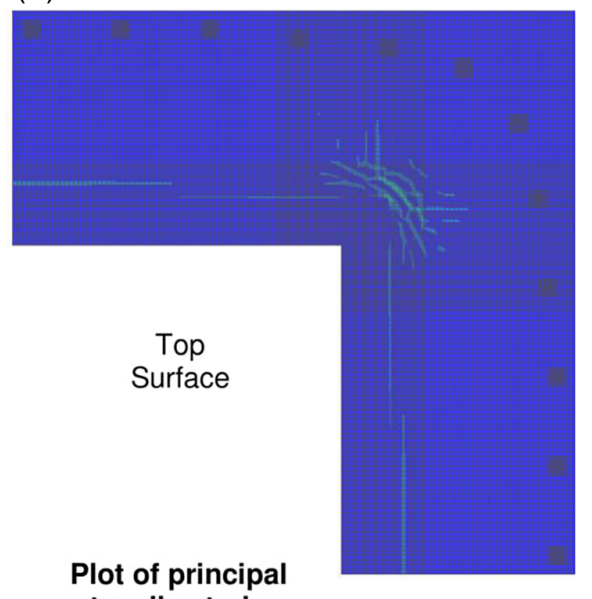

FIG URE 11 (a) Crack patterns (width $>0.1 \mathrm{~mm}$ ) and (b) plot of principal tensile strain at top and bottom surfaces of the slab. Notes: support plates not shown for clarity (a)

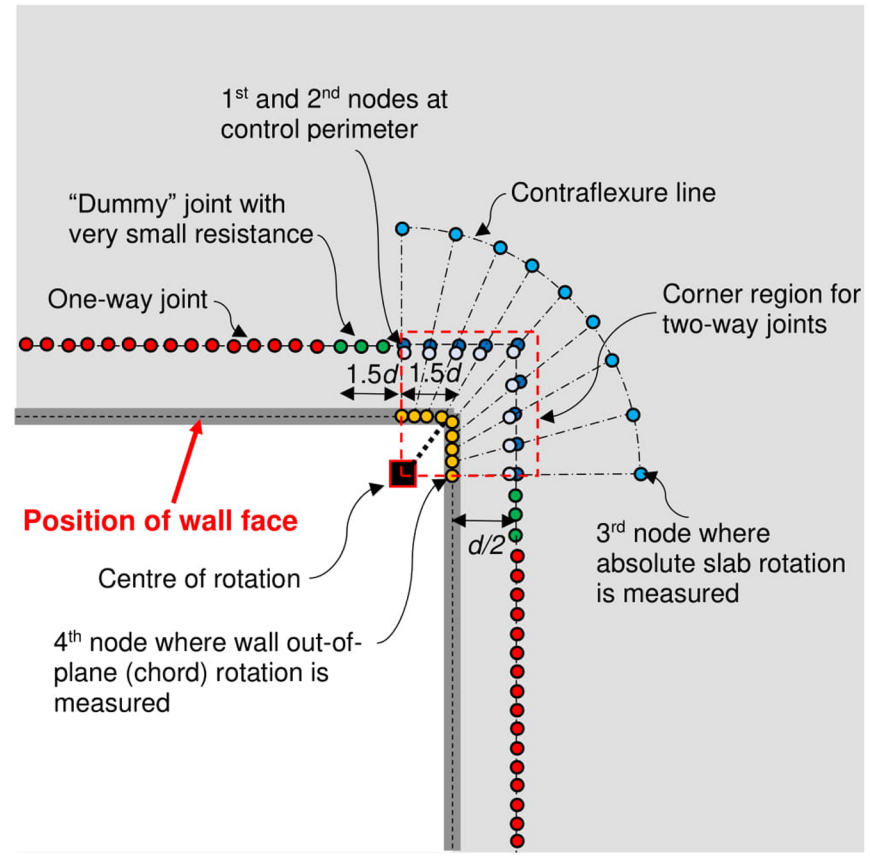

(b)

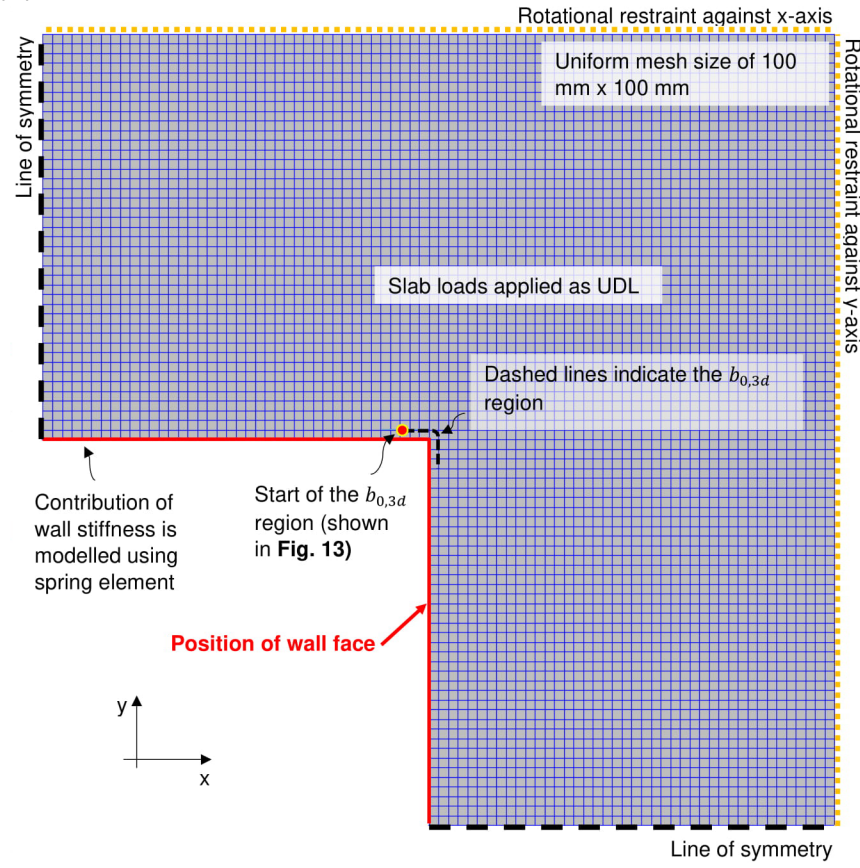

FI G U RE 12 Modeling of wall-slab model in ADAPTIC (a) Positioning of joint elements in the extended JSPM; (b) Mesh and boundary conditions 

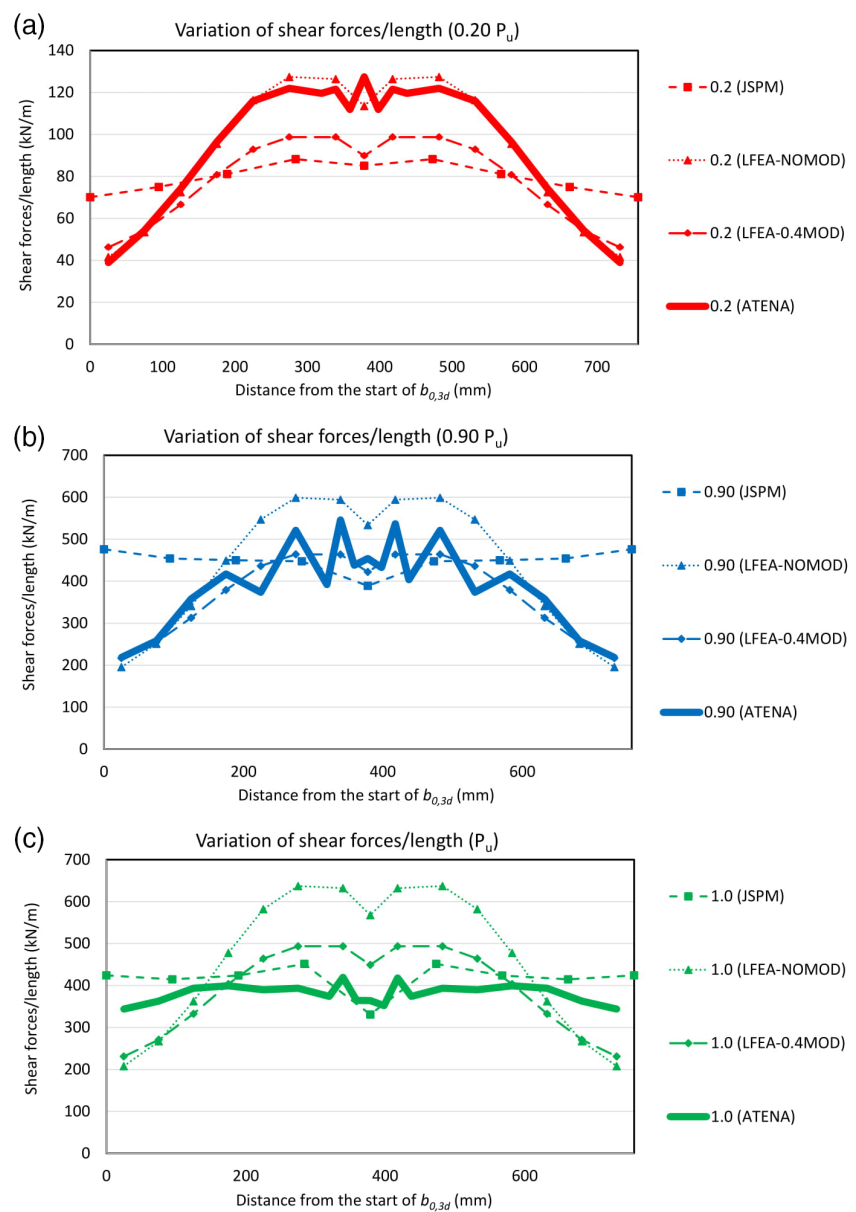

F I G U RE 13 Variation of shear force/length along the $b_{0,3 d}$ region of wall-slab model acquired using both NLFEA and LFEA at: (a) $0.20 P_{u}$; (b) $0.90 P_{u}$; and (c) $P_{u}$

LFEA as well as the joints of the JSPM. Prior to failure Figure 13 shows that a greater proportion of the total shear force is resisted around $b_{0,3 d}$ in the JSPM than estimated with either ATENA or the LFEA. Crucially, the shear force distributions around $b_{0,3 d}$ in Figure $13 \mathrm{c}$ are similar at failure for both the JSPM and ATENA. This is due to the JSPM adequately simulating the shear redistribution that occurred around $b_{0,3 d}$ near failure when the joint shear capacity is limited by the failure criterion of the CSCT. The similarity of the shear force distributions around $b_{0,3 d}$ obtained with ATENA and ADAPTIC also suggests that the difference in boundary conditions adopted in the two models had little effect on the calculated failure loads.

\section{5 | COMPARISON OF THE PROPOSED METHOD WITH NLFEA RESULTS}

The LFEA shear field based methods were evaluated by comparing their load factors, $\lambda_{V}$, at concrete shear failure with those obtained with ATENA and the JSPM. For the CSCT based methods with control perimeters at $0.5 d$ from the wall face, $\lambda_{V}$ was calculated using: (a) the average shear force along $b_{0,3 d}\left(v_{\text {wall }-a v e}\right)$ and (b) the peak design shear force derived as $\frac{v_{\text {wall }- \text { ave }}}{0.75}$. The CSCT shear resistance was calculated in terms of maximum slab rotation. For EN 1992 (2004), the critical design shear force was taken as the greatest shear force/unit length around the corner of a control perimeter at $2 d$ from the wall face.

Figure 14a,b show the resulting load factors $\lambda_{V}$ for LFEA without out-of-plane shear stiffness modifier and with modifier of 0.4 (only at $0.5 d$ ) respectively. The predictions of MC2010 LoA III and the CSCT closed-form expression $^{[16]}$ (both with default and refined LFEA parameters) agree well with the predictions of JSPM and 3-D solid analysis (ATENA) when average shear forces around $b_{0,3 d}\left(v_{\text {wall }- \text { ave }}\right)$ (depicted average forces) are used as proposed. Basing shear failure on the peak shear force $\left(\frac{v_{\text {wall }} \text {-ave }}{0.75}\right)$ (depicted MC2010 expression) is overly conservative as is the lower bound of MC2010 LoA I. The EN 1992 (2004) load factor is closest to that of ATENA. Comparison of Figure 14a,b shows that the stress field methods compare best with ATENA if a stiffness modifier of 0.4 is used as implied by Figure 13c.

\section{6 | CONCLUSION}

This paper investigates punching failure of slabs supported on elongated supports with $c_{\max } / d>6$ and wall corners. The main findings, which relate to large supports and wall corners, are as follows:

- Punching failure initiates at support corners with peak support reaction developing prior to full mobilization of shear resistance around a control perimeter at $0.5 d$ from the column face. MC2010 addresses this issue through the introduction of the effective control perimeter $b_{0,3 d}$ shown in Figure 2. For large columns $\left(c_{\max }\right)$ $d>3$ ), MC2010 assumes that the full design shear force is resisted by punching shear around $b_{0,3 d}$ with no contribution from linear shear (one-way). This approach becomes increasingly conservative as $c_{\max } / d$ increases above 6 since part of the support reaction is resisted by linear shear outside $b_{0,3 d}$.

- The joint shell punching model (JSPM) previously developed by the authors ${ }^{[9,17]}$ is shown to give comparable strength predictions for elongated columns and wall corners to NLFEA with 3-D solid elements carried out with ATENA. The advantage of the JSPM is that it is much more efficient computationally than solid element modeling. 

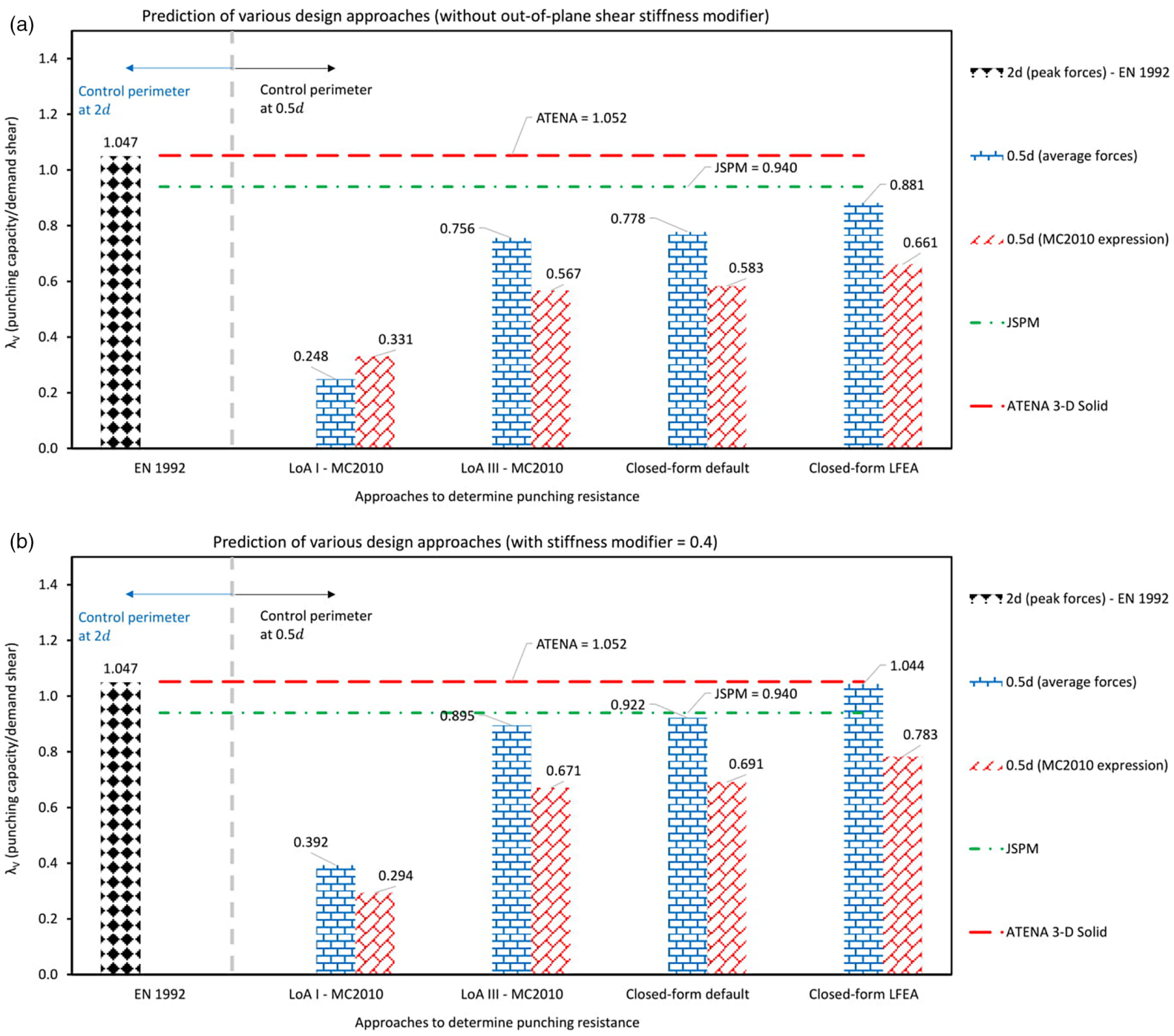

F I G U R E 14 Comparison of $\lambda_{V}$ calculated using various approaches for: (a) model without out-of-plane shear stiffness modifier and (b) model with stiffness modifier $=0.4$

- Comparison with NLFEA calibrated using test results shows that good estimates of support reaction at punching failure are obtained by taking the critical design shear stress to be used in the CSCT as the average elastic stress around the most highly stressed quadrant of $b_{0,3 d}$. This approach accounts for the contribution of one-way shear along the neglected straight lengths of $b_{0,3 d}$ unlike MC2010. Comparable results are obtained with EN 1992 (2004) if the design shear stress is taken as the peak shear stress on a control perimeter at $2 \mathrm{~d}$ from the wall face.

- Comparison with NLFEA using solid elements suggests that the out-of-plane elastic plate shear stiffness should be reduced by a multiple of 0.4 in stress field analysis but further research is required to confirm this.

\section{ACKNOWLEDGMENT}

The work presented in this article was supported by the Indonesia Endowment Fund for Education (LPDP). The opinions and conclusions in this document are those of the authors, and do not necessarily represent those of the sponsors.

\section{ORCID}

Robert L Vollum (1) https://orcid.org/0000-0003-1075-2014

\section{REFERENCES}

1. Oliveira DRC, Regan PE, Melo GSSA. Punching resistance of RC slabs with rectangular columns. Mag Concrete Res. 2004;3: 123-138.

2. Teng S, Cheong HK, Kuang KL, Geng JZ. Punching shear strength of slabs with openings and supported on rectangular columns. ACI Struct J. 2004;101(5):678-687. 
3. Sagaseta J, Tassinari L, Fernández Ruiz M, Muttoni A. Punching of flat slabs supported on rectangular columns. Eng Struct. 2014;77:17-33.

4. Einpaul J, Bujnak J, Fernández Ruiz M, Muttoni A. Study on influence of column size and slab slenderness on punching strength. ACI Struct J. 2016;113:135-145.

5. Teng S, Chanthabouala K, Lim DTY, Hidayat R. Punching shear strength of slabs and influence of low reinforcement ratio. ACI Struct J. 2018;115(1):139-150.

6. BSI. BS EN January 1, 1992:2004: Eurocode 2, design of concrete structures - Part 1-1: General rules and rules for buildings. London, UK: BSI, 2004.

7. ACI Committee 318. ACI building code requirements for structural concrete (ACI 318-14) and commentary (ACI 318R-14). Farmington Hills, MI: American Concrete Institute, 2014; p. 519.

8. fib. 2013. fib Model Code for concrete structures. Switzerland: Fédération International du Béton, Lausanne, 2010.

9. Setiawan A, Vollum RL, Macorini L, Izzuddin BA. Investigation on punching mechanism of RC slabs without transverse reinforcement supported on elongated column. Structures. 20xx; (under review).

10. Vaz Rodrigues R, Fernández Ruiz M, Muttoni A. Shear strength of R/C bridge cantilever slabs. Eng Struct. 2008;30: 3024-3033.

11. Setiawan, A. 2019. Efficient strategy for modelling punching failure of flat slabs. Thesis submitted for the degree of doctor of philosophy in the Department of Civil and Environmental Engineering, Imperial College London, London.

12. Computers and Structures, Inc. ETABS V-2017 (Student version). Integrated finite element analysis and design of structures.

13. Cervenka V, Jendele L, Cervenka J. ATENA Program Documentation, Part 1, Theory. Prague: Cervenka Consulting, 2018; p. 324.

14. Muttoni A. Punching shear strength of reinforced concrete slabs without transverse reinforcement. ACI Struct J. 2008;105 (4):440-450.

15. Sagaseta J, Muttoni A, Fernández Ruiz M, Tassinari L. Nonaxis-symmetrical punching shear around internal columns of RC slabs without transverse reinforcement. Maga Concrete Res. 2011;63(6):441-457.

16. Muttoni A, Fernández M. The theoretical principles of the critical shear crack theory for punching shear failures and derivation of consistent closed-form design expressions. Struct Concrete. 2018;19:174-190.

17. Setiawan A, Vollum RL, Macorini L, Izzuddin BA. Efficient 3-D modelling of punching shear failure at slab-column connections by means of nonlinear joint elements. Eng Struct. 2019b;197:109372.

18. Setiawan A, Vollum RL, Macorini L. Numerical and analytical investigation of internal slab-column connections subject to cyclic loading. Eng Struct. 2019a;184:535-554.

19. Milligan, G.J. and Polak, M.A. 2019. Finite element analysis of shear behaviour of concrete slabs partially supported on walls. Concrete innovations in materials, design and structures: proceedings of the 2019 fib symposium, held in Krakow, Poland, May 27-29, 2019.
20. Ferreira MP, Melo GSSA, Regan PE, Vollum RL. Punching of reinforced concrete flat slabs with double-headed shear reinforcement. ACI Struct J. 2014;111(2):363-374.

21. Broms CE. Tangential strain theory for punching failure of flat slabs. ACI Struct J. 2016;113:95-104.

22. Shu J, Belletti B, Muttoni A, Scolari M, Plos M. Internal force distribution in RC slabs subjected to punching shear. Eng Struct. 2017;153:766-781.

23. Izzuddin, B. A. 1991. Nonlinear dynamic analysis of framed Structures. Thesis submitted for the degeree of doctor of philosophy in the University of London, Department of Civil Engineering, Imperial College, London.

24. Cavagnis F, Fernández Ruiz M, Muttoni A. A mechanical model for failures in shear of members without transverse reinforcement based on development of a critical shear crack. Eng Struct. 2018;157:300-315.

25. Izzuddin BA, Tao XY, Elghazouli AY. Realistic modeling of composite and reinforced concrete floor slabs under extreme loading. Part I: Analytical method. J Struct Eng. 2004;130(12): 1972-1984.

26. Elghazouli AY, Izzuddin BA. Realistic modelling of composite and reinforced concrete floor slabs under extreme loading. Part II: Verification and application. J Struct Eng. 2004;130(12):1985-1996.

\section{AUTHOR BIOGRAPHIES}

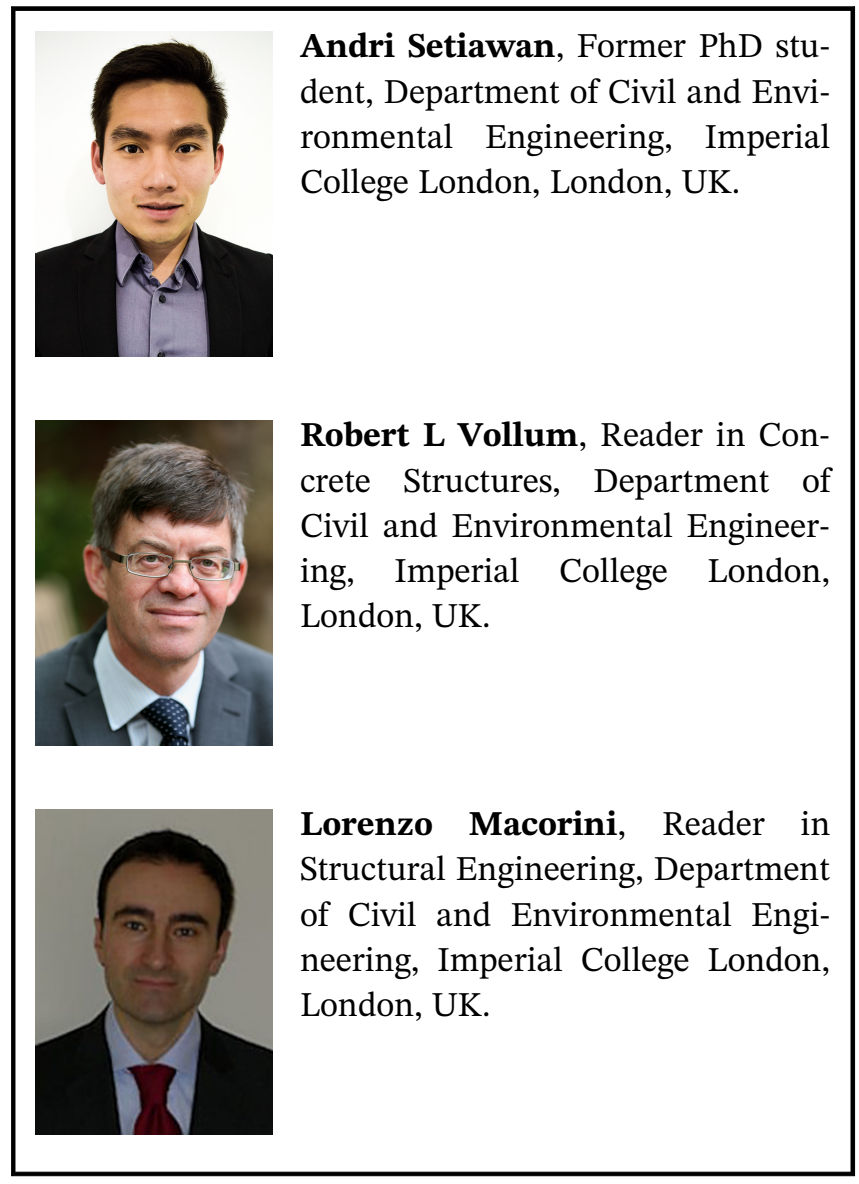




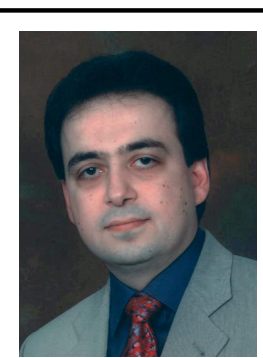

Bassam A Izzuddin, Professor of Computational Structural Mechanics, Department of Civil and Environmental Engineering, Imperial College London, London, UK.

\section{SUPPORTING INFORMATION}

Additional supporting information may be found online in the Supporting Information section at the end of this article.

How to cite this article: Setiawan A, Vollum RL, Macorini L, Izzuddin BA. Punching shear design of RC flat slabs supported on wall corners. Structural Concrete. 2020;1-16. https://doi.org/10.1002/suco. 201900514 